\title{
Satellite remote sensing analysis to monitor revegetation in the Yangtze River Basin, China
}

\author{
Boyan $\mathrm{Li}^{1}$, Wei Wang ${ }^{1}$, Chao Wang ${ }^{1}$, and Aiwen Lin ${ }^{1}$ \\ ${ }^{1}$ Wuhan University
}

June 12,2021

\begin{abstract}
Revegetation programs aim to avoid land degradation, control soil erosion, reduce floods, and improve ecological conditions. China has planted billions of trees over the past 20 years. However, little is known about the effectiveness of this artificial revegetation, and its consequences on China's national conservation policies and changes in biophysical factors at the county level. Here we use satellite time series data and develop a new metric, the revegetation index (RVI), that quickly monitors revegetation and its long-term changes. We found that the amount of regions where the Grain to Green Program (GTGP) successfully was implemented only about $55.8 \%$ of the areas of GTGP implementation. Surprisingly, we provide observational evidence that the implementation of the GTGP can decrease soil erosion and drought, and increase water availability, but revegetation in the Yangtze River Basin (YRB) in China has a limited impact on soil erosion, water and drought. In particular, for revegetation between 1999 and 2016, indicating that previous an assessment by the government revealed as official statistics may have overestimated the effects of the ecological restoration practices.
\end{abstract}

\section{Hosted file}

Manuscript.docx available at https://authorea.com/users/419450/articles/525940-satelliteremote-sensing-analysis-to-monitor-revegetation-in-the-yangtze-river-basin-china 